\title{
Regiospecific Synthesis of New Fatty $N$-Acyl Trihalomethylated Pyrazoline Derivatives from Fatty Acid Methyl Esters (FAMEs)
}

\author{
Paulo Beck, ${ }^{\#, a}$ Juliane M. dos Santos, ${ }^{a}$ Bruna L. Kuhn, ${ }^{b}$ Dayse N. Moreira, ${ }^{b}$ \\ Alex F. C. Flores, ${ }^{b}$ Marcos A. P. Martins, ${ }^{b}$ Marcelo G. M. D'Oca ${ }^{a}$ and \\ Luciana A. Piovesan $*, \#, a$ \\ ${ }^{a}$ Escola de Química e Alimentos, Universidade Federal do Rio Grande, \\ CP 474, 96201-900 Rio Grande-RS, Brazil \\ ${ }^{b}$ Departamento de Química, Universidade Federal de Santa Maria, \\ 97105-900 Santa Maria-RS, Brazil
}

\begin{abstract}
Uma série de novas pirazolinas $N$-acil trialometiladas derivadas de ésteres metílicos de ácidos graxos foi sintetizada por reação de ciclocondensação entre hidrazidas graxas e 4-alcóxi1,1,1-trialometil-3-alquen-2-onas. Ciclizações eficientes e regioespecíficas catalisadas por $\mathrm{BF}_{3} \cdot \mathrm{MeOH}$ levaram aos produtos desejados em rendimentos de bons a excelentes e alto grau de pureza.
\end{abstract}

A series of new fatty $N$-acyl trihalomethylated pyrazoline derivatives from fatty acid methyl esters was synthesized by the cyclocondensation of respective fatty hydrazides with 4-alkoxy1,1,1-trialomethyl-3-alquen-2-ones. Efficient and regiospecific cyclizations catalyzed by $\mathrm{BF}_{3} \cdot \mathrm{MeOH}$ gave the desired products in good to excellent yields and at high purity.

Keywords: $N$-acyl hydrazine, FAMEs, 4-alkoxy-1,1,1-trialomethyl-3-alquen-2-ones, $N$-acyl trialomethylated pyrazoline

\section{Introduction}

Trihalomethylated pyrazoline derivatives has been described for its inflammatory, antioxidative, hypothermic, antipyretic, analgesic, antinoceptive and a number of other properties. ${ }^{1-8}$ Since the introduction of halogens and halogenated groups into organic molecules often confers significant and useful changes in their chemical, physical and biological properties, ${ }^{9}$ the development of new methods for synthesizing halogenated compounds recently has attracted considerable interest. Among the most convenient of these methods is the use of starting materials containing halogens, including halogenated 1,3 -dieletrophiles in the form of trihalomethylated $\beta$-diketones and trihalomethylated $\alpha$ - $\beta$-unsaturated ketones (as 4-alkoxy-1,1,1-trihalo-3-alken-2-ones), which are regiospecific synthons for 5-trihalomethyl-1H-pyrazoles

*e-mail: 1piovesan@gmail.com

\#These authors contributed equally to the work. and for a variety of halomethyl-substituted heterocyclic compounds. ${ }^{10,11}$ The main synthetic method for preparing pyrazole involves $[3+2]$ cyclization, as in the classical $\beta$-diketone with hydrazines. ${ }^{12,13}$

Similarly, the introduction of fatty chains into organic molecules also can produce important changes in their chemical and physical properties. In this context, to study the influence of fatty chains on the biologic activity of organic compounds, our research group has developed methodologies for synthesizing new nitrogen molecules of pharmacological and technological interest. These molecules are structurally simple, low in cost and because of the inclusion of fatty chains have increased lipophilicity. ${ }^{14-16}$

This paper describes a synthetic method for preparing new fatty $N$-acyl trihalomethylated pyrazoline derivatives from C16:0, 18:0 and 18:1 fatty acid families. It aimed at the study of fatty molecules with biological potential, bearing in mind the synthesis of pyrazole compounds from 4-alkoxy-1,1,1-trihalo-3-alken-2-ones in close connection with this research. 


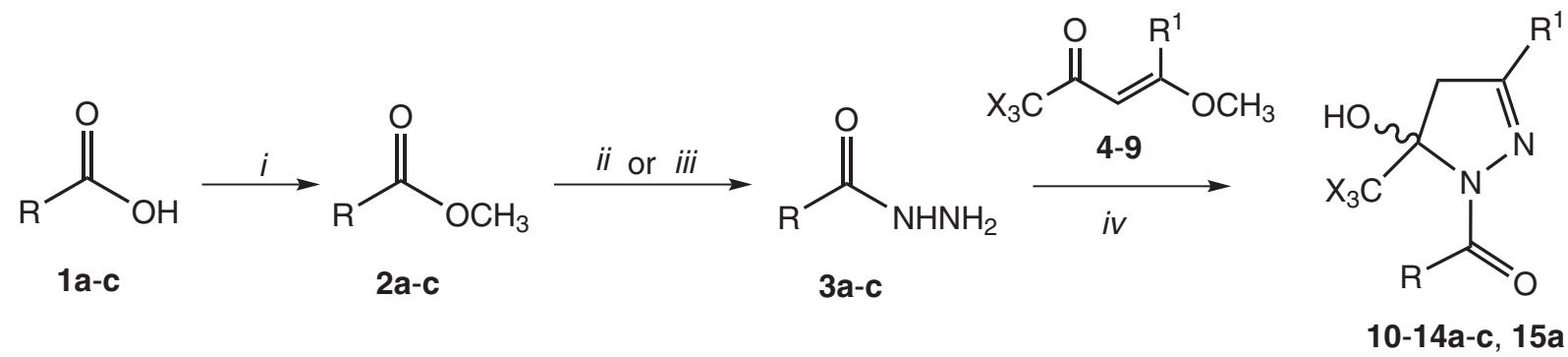

\begin{tabular}{|c|c|c|c|c|c|c|}
\hline $\mathrm{X} / \mathrm{R}^{1}$ & $4-\mathrm{CH}_{3}-\mathrm{Ph}$ & 4-Br-Ph & 4-Cl-Ph & 4-F-Ph & $4-\mathrm{OCH}_{3}-\mathrm{Ph}$ & $\mathrm{CH}_{3}$ \\
\hline $\begin{array}{l}\mathrm{Cl} \\
\mathrm{F}\end{array}$ & $\begin{array}{c}4,10 \\
-\end{array}$ & $\begin{array}{c}5,11 \\
-\end{array}$ & $\begin{array}{c}6,12 \\
-\end{array}$ & 7,13 & $8, \overline{14}$ & $\begin{array}{c}9,15 \\
-\end{array}$ \\
\hline
\end{tabular}

Scheme 1. Synthesis of the new pyrazoline derivatives 10-14a-c, 15a. Reagents and conditions: (i) $\mathrm{H}_{2} \mathrm{SO}_{4} / \mathrm{MeOH}, 65^{\circ} \mathrm{C}, 4 \mathrm{~h}$. (ii) $\mathrm{NH}_{2} \mathrm{NH}_{2} \cdot 2 \mathrm{HCl}, \mathrm{NaOCH}_{3}$, $\mathrm{MeOH}, 65^{\circ} \mathrm{C}, 24$ h. (iii) $\mathrm{NH}_{2} \mathrm{NH}_{2} \cdot \mathrm{HCl}, \mathrm{NaOH}, \mathrm{MeOH}, 65^{\circ} \mathrm{C}, 48$ h. (iv) $\mathrm{BF}_{3} \cdot \mathrm{MeOH}, 25^{\circ} \mathrm{C}, 30$ min, then $\mathrm{MeOH}, 65^{\circ} \mathrm{C}, 24 \mathrm{~h}$.

\section{Results and Discussion}

The synthetic route for the preparation of compounds 10-15 is summarized in Scheme 1 and starts from the esterification reaction of the corresponding fatty acid 1a-c, in acid medium. The progress of the esterification was monitored by silica gel thin layer chromatography (TLC) and fatty acid methyl esters (FAMEs) 2a-c were obtained with yields of $85-94 \% .{ }^{15}$

The most convenient method for preparing fatty hydrazides (fatty $N$-acyl hydrazines) from FAMEs is through a hydrazinolysis reaction using hydrazine monohydrate. ${ }^{17-20}$ Because the sale of this reagent be controlled, it was tested methods using less reactive hydrazines such as hydrazine monohydrochloridrate and hydrazine dihydrochloridrate (Table 1). The FAMEs 2a-c hydrazinolysis reaction for producing fatty $\mathrm{N}$-acyl hydrazines 3a-c was tested in the presence of two strong bases, sodium hydroxide and sodium methoxide, which release hydrazine into the reaction medium to act as a nucleophile front of the FAME.

The hydrazinolysis reactions of FAMEs 2a-c were first tested with hydrazine dihydrochloridrate. The use of pyridine, triethylamine or sodium hydroxide as a base did not result in the release of hydrazine into the medium reaction, even with an increased molar ratio of base and/or a longer reaction time. So, it was tested the use of sodium methoxide as the base. As indicated in Table 1, after a few attempts, reactions of FAME with a 3 mol equivalent of hydrazine dihydrochloridrate and a 9 mol equivalent of sodium methoxide produced pure samples of fatty $\mathrm{N}$-acyl hydrazines 3a-c in the presence of methanol under reflux for $24 \mathrm{~h}$ (entries 5-7).

Similarly, the use of pyridine or triethylamine as base for hydrazine monohydrochloridrate did not produce the desired products. Reactions of FAME with a $3 \mathrm{~mol}$ equivalent of hydrazine monohydrochloridrate and a $3 \mathrm{~mol}$ equivalent of sodium hydroxide as bases in the presence of methanol under reflux for $48 \mathrm{~h}$ yielded pure samples of fatty $N$-acyl hydrazines 3a-c (Table 1 , entries 11-13). In this case, the use of sodium methoxide did not lead to the desired products, regardless of the molar ratio or reaction time used (entries 14-19). The progress of all reactions was monitored by silica gel TLC. The raw products did not require purification and were analyzed by melting point, gas chromatography/mass spectrometry (GC/MS) and infrared (IR) spectrometry.

\section{Cyclocondensation reactions}

The 4-methoxy-1,1,1-trihalo-3-alken-2-ones 4-9 were synthesized from the reaction of appropriate enol ether or acetal with trichloroacetyl chloride or trifluoroacetic anhydride, according to the literature..$^{12,13}$

In previous reports, which related the cyclocondensation reactions between 4-alkoxy-1,1,1-trihalo-3-alken-2-ones and no-fatty $N$-acyl hydrazines, e.g., semicarbazide or tiossemicarbazide, the pyrazoline derivatives were obtained under mild conditions, methanol refluxing, with good to excellent yields (71-96\%). ${ }^{21,22}$ Initially, to prepare fatty $\mathrm{N}$-acyl trihalomethylated pyrazoline derivatives 10-15, the cyclocondensation reactions were performed from 
Table 1. Hydrazinolysis of fatty acid methyl esters $2 \mathbf{a}-\mathbf{c}$ in methanol at $65^{\circ} \mathrm{C}$

\begin{tabular}{|c|c|c|c|c|c|c|}
\hline entry & FAME & Hydrazine & Base & FAME:hydrazine:base ${ }^{a}$ & time $/ \mathrm{h}$ & Result \\
\hline 1 & $2 \mathrm{c}$ & $\mathrm{NH}_{2} \mathrm{NH}_{2} \cdot 2 \mathrm{HCl}$ & $\mathrm{NaOH}$ & $1: 3: 1$ & 24 & n.r. \\
\hline 2 & $2 \mathrm{c}$ & $\mathrm{NH}_{2} \mathrm{NH}_{2} \cdot 2 \mathrm{HCl}$ & $\mathrm{NaOH}$ & $1: 3: 1$ & 24 & n.r. \\
\hline 3 & $2 \mathrm{c}$ & $\mathrm{NH}_{2} \mathrm{NH}_{2} \cdot 2 \mathrm{HCl}$ & $\mathrm{NaOMe}$ & $1: 3: 3$ & 24 & n.r. \\
\hline 4 & $2 c$ & $\mathrm{NH}_{2} \mathrm{NH}_{2} \cdot 2 \mathrm{HCl}$ & $\mathrm{NaOMe}$ & $1: 3: 3$ & 24 & $2 c+3 c$ \\
\hline 5 & $2 a$ & $\mathrm{NH}_{2} \mathrm{NH}_{2} \cdot 2 \mathrm{HCl}$ & $\mathrm{NaOMe}$ & 1:3:9 & 24 & 3a, $80 \%$ \\
\hline 6 & $2 \mathbf{b}$ & $\mathrm{NH}_{2} \mathrm{NH}_{2} \cdot 2 \mathrm{HCl}$ & $\mathrm{NaOMe}$ & $1: 3: 9$ & 24 & $3 \mathbf{b}, 80 \%$ \\
\hline 7 & $2 c$ & $\mathrm{NH}_{2} \mathrm{NH}_{2} \cdot 2 \mathrm{HCl}$ & $\mathrm{NaOMe}$ & 1:3:9 & 24 & 3c, $69 \%$ \\
\hline 8 & $2 c$ & $\mathrm{NH}_{2} \mathrm{NH}_{2} \cdot \mathrm{HCl}$ & $\mathrm{NaOH}$ & $1: 3: 1$ & 24 & n.r. \\
\hline 9 & $2 c$ & $\mathrm{NH}_{2} \mathrm{NH}_{2} \cdot \mathrm{HCl}$ & $\mathrm{NaOH}$ & $1: 3: 1$ & 48 & n.r. \\
\hline 10 & $2 c$ & $\mathrm{NH}_{2} \mathrm{NH}_{2} \cdot \mathrm{HCl}$ & $\mathrm{NaOH}$ & $1: 3: 3$ & 24 & n.r. \\
\hline 11 & $2 \mathbf{a}$ & $\mathrm{NH}_{2} \mathrm{NH}_{2} \cdot \mathrm{HCl}$ & $\mathrm{NaOH}$ & $1: 3: 3$ & 48 & 3a, $80 \%$ \\
\hline 12 & $2 \mathbf{b}$ & $\mathrm{NH}_{2} \mathrm{NH}_{2} \cdot \mathrm{HCl}$ & $\mathrm{NaOH}$ & $1: 3: 3$ & 48 & $3 \mathbf{b}, 80 \%$ \\
\hline 13 & $2 c$ & $\mathrm{NH}_{2} \mathrm{NH}_{2} \cdot \mathrm{HCl}$ & $\mathrm{NaOH}$ & $1: 3: 3$ & 48 & 3c, $69 \%$ \\
\hline 14 & $2 \mathrm{c}$ & $\mathrm{NH}_{2} \mathrm{NH}_{2} \cdot \mathrm{HCl}$ & $\mathrm{NaOMe}$ & $1: 3: 3$ & 24 & n.r. \\
\hline 15 & $2 \mathrm{c}$ & $\mathrm{NH}_{2} \mathrm{NH}_{2} \cdot \mathrm{HCl}$ & $\mathrm{NaOMe}$ & $1: 3: 6$ & 24 & n.r. \\
\hline 16 & $2 c$ & $\mathrm{NH}_{2} \mathrm{NH}_{2} \cdot \mathrm{HCl}$ & $\mathrm{NaOMe}$ & 1:3:9 & 24 & n.r. \\
\hline 17 & $2 c$ & $\mathrm{NH}_{2} \mathrm{NH}_{2} \cdot \mathrm{HCl}$ & $\mathrm{NaOMe}$ & $1: 3: 3$ & 48 & n.r. \\
\hline 18 & $2 \mathrm{c}$ & $\mathrm{NH}_{2} \mathrm{NH}_{2} \cdot \mathrm{HCl}$ & $\mathrm{NaOMe}$ & $1: 3: 6$ & 48 & n.r. \\
\hline 19 & $2 c$ & $\mathrm{NH}_{2} \mathrm{NH}_{2} \cdot \mathrm{HCl}$ & $\mathrm{NaOMe}$ & $1: 3: 9$ & 48 & $2 c+3 c$ \\
\hline
\end{tabular}

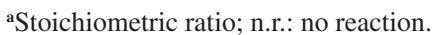

fatty $\mathrm{N}$-acyl hydrazines 3a-c and enones 4-9 through mild conditions in refluxing methanol with a reaction time of $12 \mathrm{~h}$. However, the presence of a strong electronwithdrawing substituent at the N1 of 1,2-dinucleophile makes it less reactive. This is because the electron pairs of nitrogen atoms are in resonance with the carbonyl group and demand more specific reaction conditions. When inorganic acids such as $\mathrm{H}_{2} \mathrm{SO}_{4}$ and $\mathrm{HCl}$ were used as catalysts, it was observed substrates even after a reaction time of $72 \mathrm{~h}$. Therefore, $\mathrm{BF}_{3} \cdot \mathrm{MeOH}$ was tested as a Lewis acid catalyst. It was first added a catalyst into a solution of enone in methanol and immediately added the fatty $\mathrm{N}$-acyl hydrazine; no product was formed even after a reaction time of $24 \mathrm{~h}$. When fatty $\mathrm{N}$-acyl hydrazine was added after 15 min, the product did form, and substrates were observed by TLC. When fatty $N$-acyl hydrazine was added at $30 \mathrm{~min}$ after the addition of catalyst, pure samples of 10-14a-c and 15a were recovered after a reaction time of $24 \mathrm{~h}$.

The structures of the new fatty $N$-acyl trihalomethylated pyrazoline derivatives were confirmed by IR and ${ }^{1} \mathrm{H}$ and ${ }^{13} \mathrm{C}$ nuclear magnetic resonance (NMR) spectral data. The ${ }^{1} \mathrm{H}$ and ${ }^{13} \mathrm{C}$ NMR spectra of products 10-14a-c and 15a showed one set of signals corresponding to the proposed structures. ${ }^{12,13}$ ${ }^{1} \mathrm{H}$ NMR showed signals for the diastereotopic protons $\mathrm{H} 4 \mathrm{a}$ and $\mathrm{H} 4 \mathrm{~b}$ of $\mathrm{C} 4$ as two doublets at 3.3-3.5 ppm $(J \mathrm{ca} .19 \mathrm{~Hz})$.
This behavior demonstrates the presence of a stereogenic center (C5) neighboring $\mathrm{C} 4$ and confirms that the structures are 4,5-dihydropyrazoles. Previous studies demonstrated that the doublet with greater deshielding corresponds to the hydrogen at $\mathrm{C} 4$, which is cis relative to $\mathrm{OH}$ at $\mathrm{C}^{23} .^{232} \mathrm{In}$ addition, the spectral data showed typical chemical shifts for the alkyl substituent at C3 (15a) or aryl substituent (1014a-c) and for fatty-chain hydrogens.

As observed in other studies using hydrazides to synthesize pyrazoles from 4-alkoxy-1,1,1-trihalo-3-alken-2-ones, the chain derived from the fatty acid linked to the $\mathrm{N} 1$ of the pyrazoline ring acts as a protecting group for its electronwithdrawing effect, preventing water elimination and the subsequent aromatization of the pyrazoline ring, producing a pyrazole. ${ }^{21,22,25-27} \mathrm{Also}$, the presence of a trihalomethylated group at the vinyl ketone and the chain derived from the fatty acid at the dinucleophile were crucial for the regiochemistry of the reactions, which produced only the 5-trihalomethylated isomers. The suggested pathway to the cyclocondensation reaction is shown in Scheme 2. Whereas the precursors 4-alkoxy-1,1,1-trihalo-3-alken-2-ones are molecules composed by a block CCC with two eletrofilic centers with distinguished reactivity, and the hydrazines are very reactive front to $\mathrm{sp}^{2}$ carbon atoms, the first step is the nucleophilic attack of unsubstituted nitrogen of hydrazine 


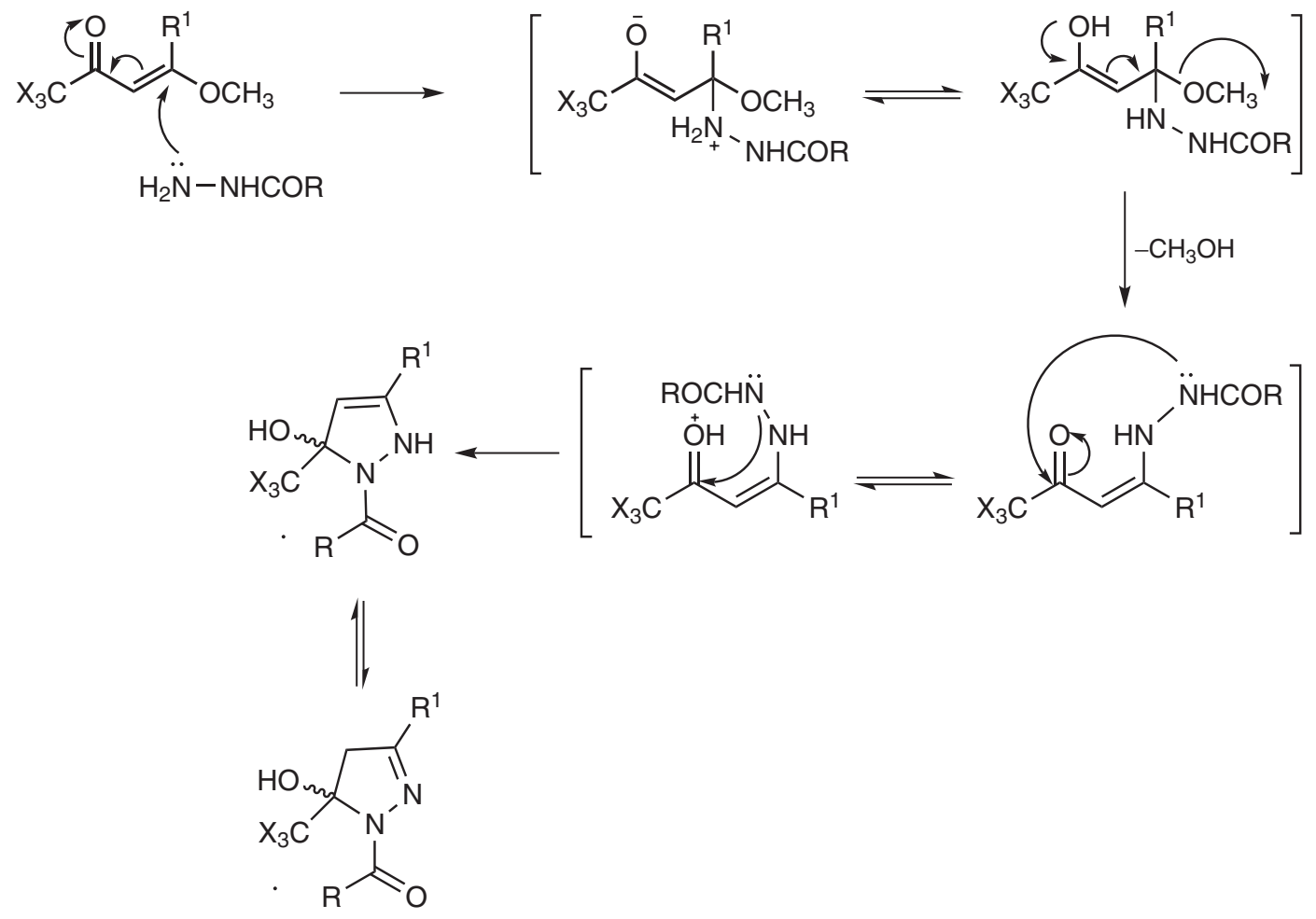

Scheme 2. Mechanism proposed to the pyrazoline derivative synthesis.

Table 2. Synthesis of new fatty $N$-acyl trihalomethylated pyrazoline derivatives

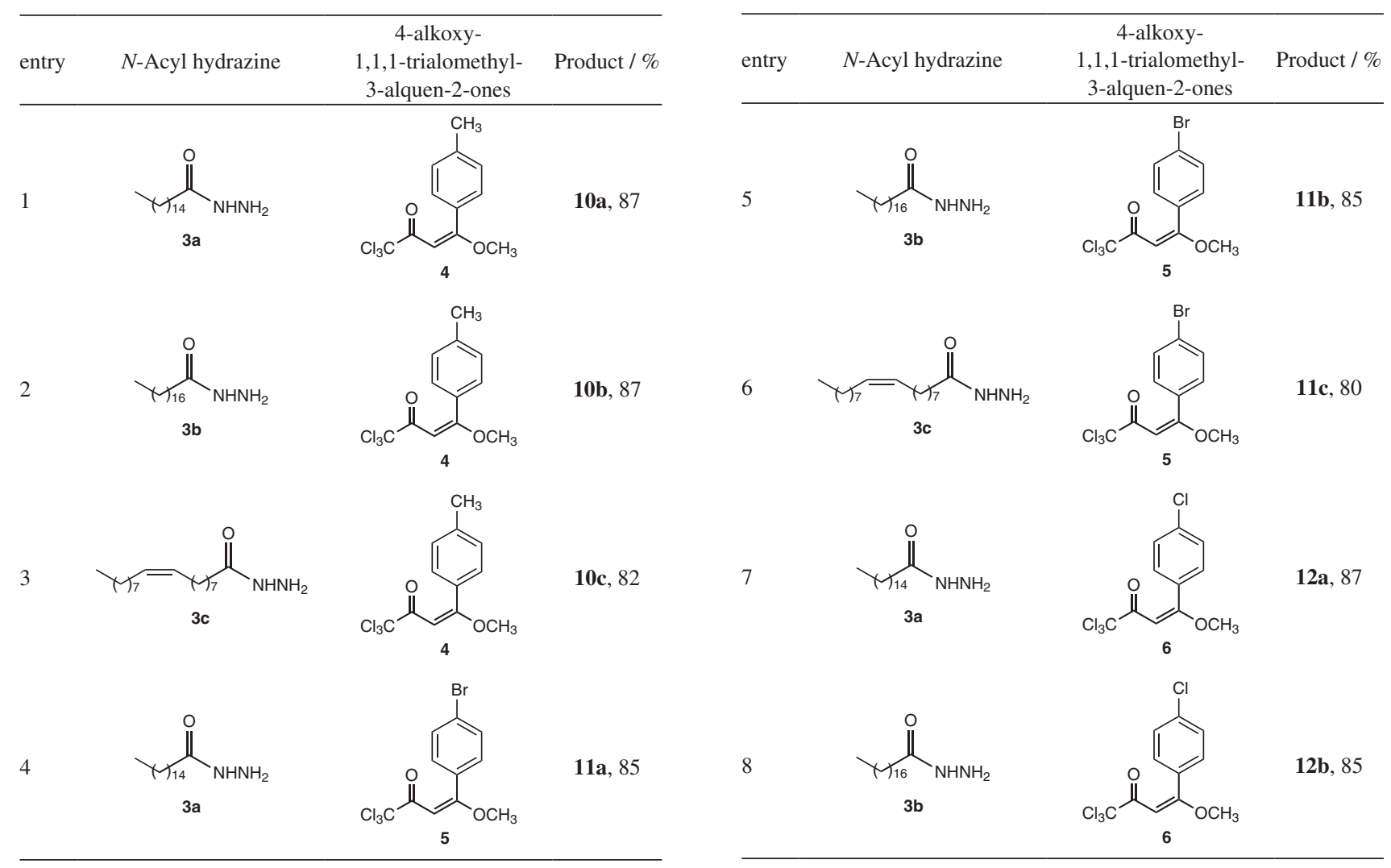


Table 2. continuation

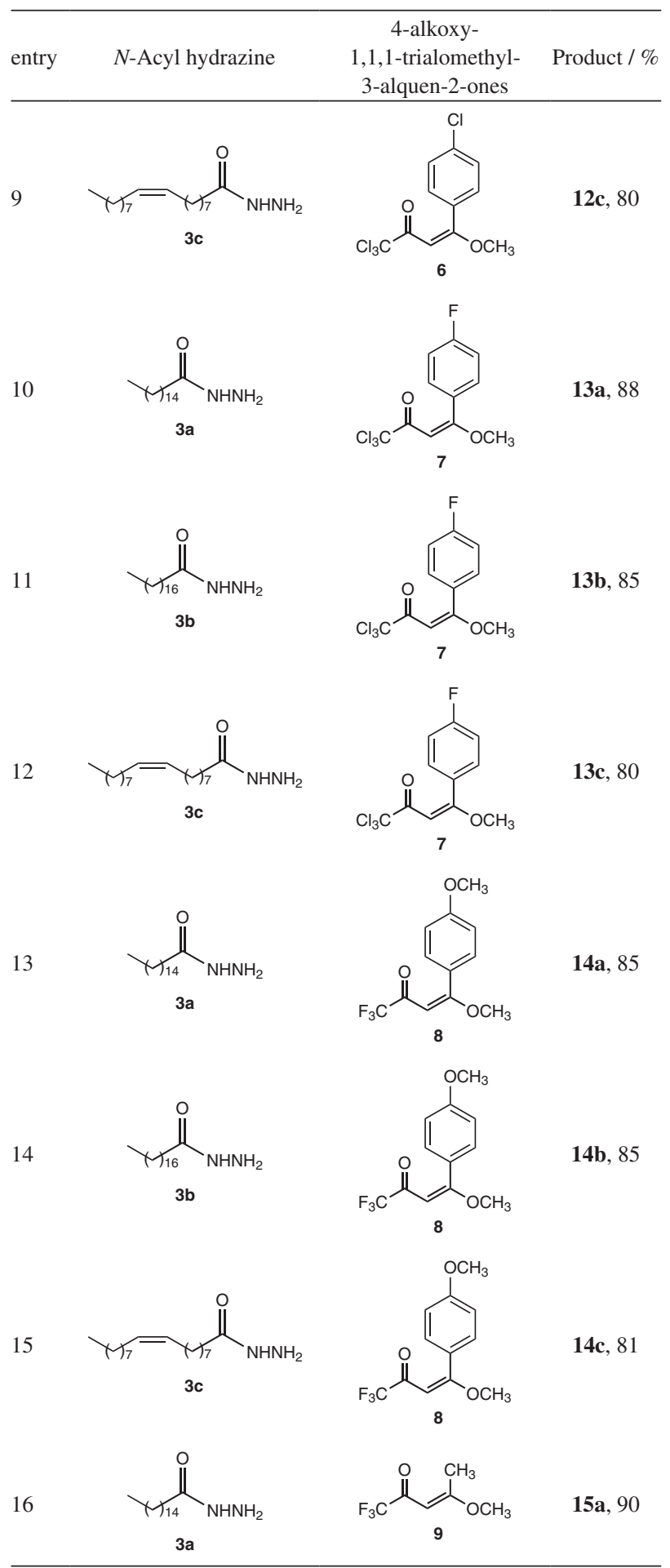

to $C \beta$. The loss of the methoxyl group leads to intermediate enaminone-type. Then, there is the intramolecular nucleophilic attack of the second nitrogen of hydrazine to the trialomethyl-substituted carbonyl carbon to form the pyrazoline nucleus. Table 2 provides the structures and yields of all of the newly synthesized compounds.

\section{Conclusions}

In conclusion, this work demonstrates the synthesis of fatty hydrazides from FAMEs. The new methodology produces hydrazide derivatives from C16:0, 18:0 and 18:1 fatty acids with high yields and purity; the compounds used as 1,2-dinucleophile precursors in regiospecific cyclocondensation reactions with several 4-alkoxy-1,1,1-trihalo-3-alken-2-ones give rise to fatty $\mathrm{N}$-acyl trihalomethylated pyrazoline derivatives. The new compounds were synthesized through efficient catalysis with $\mathrm{BF}_{3} \cdot \mathrm{MeOH}$ with good to excellent yields $(80-90 \%)$ and high purity.

\section{Supplementary Information}

Experimental procedures, data spectra and spectra of synthesized compounds are available free of charge at http://jbcs.sbq.org.br as a PDF file.

\section{Acknowledgments}

The authors are thankful for the financial support from the Coordenação de Aperfeiçoamento de Pessoal de Nível Superior (CAPES), Fundação de Apoio à Pesquisa do Estado do Rio Grande do Sul (FAPERGS) and the Conselho Nacional de Desenvolvimento Científico e Tecnológico (CNPq). Fellowships from CAPES (P. Beck, J. M. dos Santos and L. A. Piovesan) are also acknowledged.

\section{References}

1. Penning, T. D.; Talley, J. J.; Bertenshaw, S. R.; Carter, J. S.; Collins, P. W.; Docter, S.; Graneto, M. J.; Lee, L. F.; Malecha, J. W.; Miyashiro, J. M.; Rogers, R. S.; Rogier, D. J.; Yu, S. S.; Anderson, G. D.; Burton, E. G.; Cogburn, J. N.; Gregory, S. A.; Koboldt, C. M.; Perkins, E. R.; Seibert, K.; Veenhuizen, A. W.; Zhang, Y. Y.; Isakson, P. C.; J. Med. Chem. 1997, 40, 1347.

2. Souza, F. R.; Ratzlaff, V. T.; Borges, L. P.; Oliveira, M. R.; Bonacorso, H. G.; Zanatta, N.; Martins, M. A. P.; Mello, C. F.; Eur. J. Pharmacol. 2002, 451, 141.

3. Godoy, M. C. M.; Fighera, M. R.; Souza, F. R.; Flores, A. E.; Rubin, M. A.; Oliveira, M. R.; Zanatta, N.; Martins, M. A. P.; Bonacorso, H. G.; Mello, C. F.; Eur. J. Pharmacol. 2004, 496, 93.

4. Milano, J.; Oliveira, S. M.; Rossato, M. F.; Sauzem, P. D.; Machado, P.; Beck, P.; Zanatta, N.; Martins, M. A. P.; Mello, C. F.; Rubin, M. A.; Ferreira, J.; Bonacorso, H. G.; Eur. J. Pharmacol. 2008, 581, 86. 
5. Sauzem, P. D.; Machado, P.; Rubin, M. A.; Sant'Anna, G. S.; Faber, H. B.; Souza, A. H.; Mello, C. F.; Beck, P.; Burrow, R. A.; Bonacorso, H. G.; Zanatta, N.; Martins, M. A. P.; Eur. J. Med. Chem. 2008, 43, 1237.

6. Martins, D. M.; Torres, B. G.; Spohr, P. R.; Machado P.; Bonacorso, H. G.; Zanatta, N.; Martins, M. A. P.; Emanuelli, T.; Basic Clin. Pharmacol. 2009, 104, 107.

7. Sauzem, P. D.; Sant'Anna, G. S.; Machado, P.; Duarte, M. M. M. F.; Ferreira, J.; Mello, C. F.; Beck, P.; Bonacorso, H. G.; Zanatta, N.; Martins, M. A. P.; Rubin, M. A.; Eur. J. Pharmacol. 2009, 616, 91.

8. Pasin, J. S. M.; Ferreira, A. P. O.; Saraiva, A. L. L.; Ratzlaff, V.; Andrighetto, R.; Machado, P.; Marchesan, S.; Zanette, R. A.; Bonacorso, H. G.; Zanatta, N.; Martins, M. A. P.; Ferreira, J.; Mello, C. F.; Braz. J. Med. Biol. Res. 2010, 43, 1193.

9. Kirk, K. L.; J. Fluorine Chem. 2006, 127, 1013, and references cited herein.

10. Druzhinin, S. V.; Balenkova, E. S.; Nenajdenko, V. G.; Tetrahedron 2007, 63, 7753, and references cited herein.

11. Nenajdenko, V. G.; Balenkova, E. S.; ARKIVOC 2011, i, 246, and references cited herein.

12. Martins, M. A. P.; Cunico, W.; Pereira, C. M. P.; Flores, A. F. C.; Bonacorso, H. G.; Zanatta, N.; Curr. Org. Synth. 2004, 1, 391 , and references cited herein.

13. Martins, M. A. P.; Machado, P.; Rosa, F. A.; Cunico, W.; Bonacorso, H. G.; Zanatta, N.; Mini-Rev. Org. Chem. 2008, 5, 53 , and references cited herein.

14. D’Oca, C. R. M.; Marinho, T. G.; Hack, C. R. L.; Duarte, R. C.; D’Oca, M. G. M.; Coelho T.; da Silva, P. A.; Bioorg. Med. Chem. Lett. 2010, 20, 5255.

15. D’Oca, M. G. M.; Lopes, C. R.; Ros, C.; Duarte, R. C.; Kurz, M. H. S.; Primel, E. G.; Clementin, R. M.; Villareyes, J. A. M.; Quím. Nova 2010, 33, 1335.
16. Duarte, R. C.; Ongaratto, R.; Piovesan, L. A.; Lima, V. R.; Soldi, V.; Merlo, A. A.; D’Oca, M. G. M.; Tetrahedron Lett. 2012, 53, 2454.

17. Rauf, A.; Sharma, S.; Gangal, S.; ARKIVOC 2007, 16, 137.

18. Awasthi, S.; Rishishwar, P.; Rao, A. N.; Ganesan, K.; Malhotra, R. C.; J. Korean Chem. Soc. 2007, 51, 506.

19. Rauf, A.; Bandaya, M. R.; Mattoob, R. H.; Acta Chim. Slov. 2008, 55, 448.

20. Banday, M. R.; Mattoo, R. H.; Rauf, A.; J. Chem. Sci. 2010, 122, 177.

21. Bonacorso, H. G.; Wastowski, A. D.; Zanatta, N.; Martins, M. A. P.; Naue, J. A.; J. Fluorine Chem. 1998, 92, 23.

22. Bonacorso, H. G.; Oliveira, M. R.; Wentz, A. P.; Wastowski, A. D.; Hoerner, M.; Zanatta, N.; Martins, M. A. P.; Tetrahedron 1999, 55, 345.

23. Flores, A. F. C.; Siqueira, G. M.; Freitag, R.; Zanatta, N.; Martins, M. A. P.; Quím. Nova 1994, 17, 298.

24. Martins, M. A. P.; Zoch, A.; Zanatta, N.; Flores, A. F. C.; Spectrosc. Lett. 1997, 30, 661.

25. Martins, M. A. P.; Flores, A. F. C.; Bastos, G. P.; Sinhorin, A.; Bonacorso, H. G.; Zanatta, N.; Tetrahedron Lett. 2000, 41, 293.

26. Martins, M. A. P.; Sinhorin, A.; Zimmermann, N. E. K.; Zanatta, N.; Bonacorso, H. G.; Bastos, G. P.; Synthesis 2001, 1959.

27. Martins, M. A. P.; Sinhorin, A. P.; Rosa, A.; Flores, A. F. C.; Wastowski, A. D.; Pereira, C. M. P.; Flores, D. C.; Beck, P.; Freitag, R. A.; Brondani, S.; Cunico, W.; Bonacorso, H. G.; Zanatta, N.; Synthesis 2002, 2353.

Submitted: April 11, 2012 Published online: November 6, 2012 